SIMÕES AC; ALVES GKEB; FERREIRA RLF; ARAUJO NETO SE. 2015. Qualidade da muda e produtividade de alface orgânica com condicionadores de substrato. Horticultura Brasileira 33: 521-526. DOI - http://dx.doi.org/10.1590/S0102-053620150000400019

\title{
Qualidade da muda e produtividade de alface orgânica com condicionadores de substrato
}

\author{
Antônio C Simões; Gisley KEB Alves; Regina LF Ferreira; Sebastião E Araújo Neto \\ Universidade Federal do Acre (UFAC), Rio Branco-AC, Brasil; ttoni_23@hotmail.com; gisley_karoline@hotmail.com; reginalff@ \\ yahoo.com.br; selviro2000@yahoo.com.br
}

\section{RESUMO}

O uso dos resíduos orgânicos como componentes de substrato para produção de mudas de hortaliças propicia a obtenção de materiais alternativos, de fácil disponibilidade e baixo custo. O objetivo do trabalho foi avaliar o efeito de condicionadores de substratos na qualidade da muda orgânica e o efeito dessas mudas sobre a produtividade da alface em sistema orgânico. O delineamento experimental foi em blocos casualizados com seis tratamentos e quatro repetições. Os tratamentos constaram dos substratos orgânicos compostos de casca de arroz carbonizada (T1), fibra casca de coco (T2), composto orgânico (T3), substrato comercial Golden ${ }^{\circledR}$ utilizado como tratamento controle (T4), estipe de palmeira picado (T5) e caule decomposto de sumaúma (T6). A cultivar utilizada (Vera) possui folhas crespas e soltas, com coloração verde-claras adaptada a clima quente. Foi instalado um experimento em viveiro e outro em campo, ambos em delineamento de blocos ao acaso com quatro repetições, sendo a unidade experimental de 10 mudas no viveiro e seis planta em campo, realizados no período de março a abril de 2013 em cultivo protegido em Rio Branco-AC. Avaliou-se aos 24 dias após a semeadura o índice de qualidade das mudas (IQD), a massa seca das partes aérea e raiz. No experimento a campo, aos 45 dias após o transplantio, avaliou-se a massa seca da parte aérea, massa fresca comercial e produtividade da alface. O substrato contendo estipe de palmeira como condicionador produziu mudas com maior índice de qualidade, seguido dos condicionadores casca de arroz carbonizada, fibra de casca de coco, composto orgânico e caule decomposto de sumaúma que não diferiram entre si. Os substratos contendo casca de arroz carbonizada, fibra de casca de coco, sumaúma e palmeira, proporcionam maior massa fresca comercial (220; 230; 207 e $208 \mathrm{~g}$ / planta, respectivamente), massa seca da parte aérea e produtividade $\left(2,44 ; 2,56 ; 2,30\right.$ e $2,31 \mathrm{~kg} / \mathrm{m}^{2}$, respectivamente $)$ da alface em sistema orgânico de produção, podendo ser substituídos entre si sem perda de produtividade.

Palavras-chave: Lactuca sativa, propagação de hortaliças, agricultura orgânica.

\begin{abstract}
Seedling quality and yield of organic lettuce using different substrate conditioners

The use of organic wastes as components of substrate on the production of vegetable seedlings allows to obtain alternative materials, easily available and with low cost. We evaluated the effect of substrate conditioners on the quality of organic seedlings and the effect of these seedlings on the yield of lettuce in organic system. The experimental design was randomized blocks with six treatments and four replications. Treatments consisted of the organic substrates carbonized rice husk (T1), coconut shell fiber (T2), organic compost (T3), commercial substrate Golden ${ }^{\circledR}$ used as control treatment (T4); chopped palm stipe (T5) and decomposed kapok stem (T6). The cultivar used (Vera) is characterized by curly and loose leaves with light green color adapted to hot weather. An experiment was carried out in a greenhouse and another in the field, both following the randomized blocks design, with four replications, and the experimental unit of 10 seedlings in the greenhouse and six plants in the field, from March to April 2013, under protected environment in Rio Branco, Acre State, Brazil. At 24 days after sowing, we evaluated the seedling quality index (IQD), dry mass of aboveground part and roots of the seedlings. In the field experiment, 45 days after transplanting, we evaluated the dry mass of the aboveground part, marketable fresh weight and yield of the plants. The substrate containing chopped palm stipe as conditioner produced seedlings with the highest quality, followed by carbonized rice husk, coconut shell fiber, organic compost, and decomposed kapok stem with no difference among them. The substrates containing carbonized rice husk, coconut shell fiber, decomposed kapok stem and chopped palm stipe provided greater marketable fresh weight $(220 ; 230 ; 207$ and $208 \mathrm{~g} /$ plant, respectively), dry weight of aboveground part and yield $\left(2.44 ; 2.56 ; 2.30\right.$ and $2.31 \mathrm{~kg} / \mathrm{m}^{2}$, respectively) on the organic production system. Thus, alternating those substrates is possible, without loss of productivity.
\end{abstract}

Keywords: Lactuca sativa, vegetable propagation, organic agriculture.

(Recebido para publicação em 7 de agosto de 2014; aceito em 6 de maio de 2015) (Received on August 7, 2014; accepted on May 6, 2015)

\begin{abstract}
A alface (Lactuca sativa) é uma planta anual, originária de clima temperado, destaca-se entre as hortaliças folhosas mais consumidas no mundo na forma de salada, tanto pelo seu sabor
\end{abstract}

e qualidade nutricional quanto pelo seu baixo custo (Filgueira, 2008).

O cultivo orgânico de hortaliças tem crescido na mesma proporção que o seu consumo. Barbosa et al. (2011), em pesquisa na cidade de Goiânia, relataram que $69 \%$ das pessoas entrevistadas consomem produtos orgânicos e $92,6 \%$ têm conhecimento desses alimentos. Esses entrevistados alegam que o consumo é 
motivado pela qualidade do alimento, isenção de agrotóxicos e pela conservação ambiental do agroecossistema, mas que primeiramente o preço e depois a variabilidade e oferta dos produtos reduzem seu consumo. A alface orgânica caracteriza-se pelo teor de vitamina $\mathrm{C}$, maior que das alfaces hidropônicas e convencional e menor teor de nitrato (Silva et al., 2011).

A agricultura orgânica tem como princípio o manejo ecológico da fauna e flora no agroecossistema, com responsabilidade social, equilíbrio econômico e segurança alimentar. Para isso, utiliza controle biológico de pragas e doenças, fertilizantes orgânicos, fertilizantes químicos de baixa concentração e solubilidade, cobertura de solo, plantio direto dentre outras práticas conservacionista (Souza \& Resende, 2006).

$\mathrm{Na}$ agricultura orgânica é obrigatório o uso de mudas e sementes orgânicas $\left(\right.$ Lei $\left.^{\circ}{ }^{\circ} 10.831,2003\right)$. Uma das dificuldades no cultivo orgânico de hortaliças é obter mudas de boa qualidade em recipientes. Sabe-se que o reduzido volume do substrato, a proibição do uso de fertilizantes químicos de altas concentração e solubilidade contida nos substratos comerciais, podem proporcionar mudas de baixa qualidade (Souza \& Resende, 2006).

Além da composição química, as características físicas são importantes em substratos para plantas (Ferraz et al., 2005). Estas características físicas são proporcionadas por condicionadores, que podem ser comercializados ou produzidos a partir de resíduos orgânicos como fibra de casca de coco, casca de arroz carbonizada, fibra de caule de palmeira, composto orgânico dentre outros, melhorando a qualidade de mudas de almeirão (Pereira et al., 2012), brócolis (Lopes et al., 2012), tomateiro (Costa et al., 2007; Rodrigues et al., 2010) e alface (Castoldi et al., 2014).

O composto orgânico pode apresentar alta concentração de nutrientes como, cálcio, magnésio, fósforo e propriedades físicas/hídricas adequadas. Este material apresenta também alta capacidade de troca de cátions e teores elevados de matéria orgânica (Cardoso et al., 2011).

Dentre os componentes do substrato responsáveis pela melhoria das proprie- dades químicas, tem-se o composto orgânico e os fertilizantes permitidos pela legislação de orgânicos como calcário, fosfatos naturais, sulfato de potássio e micronutrientes. Casca de arroz carbonizada, fibra de coco, fibra de estipes, resíduos de madeira decompostos ou vermiculita podem ser utilizados como condicionadores, pois apresentam boa densidade, porosidade e retenção de umidade (Costa et al., 2007; Trani et al., 2007; Barreto et al., 2011; Farias et al., 2012).

Entre vários materiais utilizados na mistura de substratos, a casca de arroz carbonizada pode ser utilizada como condicionador por não reagir com os nutrientes do solo, por apresentar longa durabilidade sem se degradar e por proporcionar boa retenção de umidade (Freitas et al., 2013).

A necessidade de diversificação de condicionadores de substrato no estado do Acre faz-se pela sua distância entre os centros produtores de substrato, indisponibilidade e baixa produção, sazonalidade de casca de arroz e inexistência de agroindústria de coco. Porém, existe boa produção de outros resíduos como caule de palmeira (ouricurí, pupunha e açaí), resíduos de madeira, casca de cupuaçu ou mandioca que podem ser utilizados.

Diante do exposto, o objetivo deste trabalho foi avaliar o efeito de diferentes condicionadores de substratos na qualidade da muda orgânica e o efeito dessas mudas sobre a produtividade da alface em sistema orgânico.

\section{MATERIAL E MÉTODOS}

Para avaliação dos substratos (condicionadores), foram instalados dois experimentos: o primeiro com produção de mudas em viveiro e o segundo em campo com mudas produzidas nos mesmo substratos.

O experimento foi implantado no Sítio Ecológico Seridó, localizado na Rod. AC-10, km 4, em Rio Branco-AC (9॰53'11'S, 6749'9''O, altitude $170 \mathrm{~m}$ ), de março a maio de 2013. O clima, segundo a classificação de Köppen, é do tipo Am, clima equatorial com variação para o tropical quente e úmido, com estação seca bem definida, junho/setembro, temperaturas médias anuais em torno de $24,5^{\circ} \mathrm{C}$, umidade relativa do ar $84 \%$, precipitação anual de 1.700 a $2.400 \mathrm{~mm}$.

O solo do experimento é classificado como ARGISSOLO AMARELO Distrófico plíntico (Embrapa, 2013). Após cinco anos de cultivo orgânico, o solo apresentava a composição química, na camada de 0-20 cm: $\mathrm{pH}=5,6$; M.O.=51,3 g/dm 3 ; $=256,5 \mathrm{mg} / \mathrm{dm}^{3}$; $\mathrm{K}=8,1 \mathrm{mmol}_{\mathrm{c}} / \mathrm{dm}^{3} ; \mathrm{Ca}=87,5 \mathrm{mmol}_{\mathrm{c}} /$ $\mathrm{dm}^{3} ; \mathrm{Mg}=58 \mathrm{mmol}_{\mathrm{c}} / \mathrm{dm}^{3} ; \mathrm{Al}=0,00$ $\mathrm{mmol}_{\mathrm{c}} / \mathrm{dm}^{3} ; \mathrm{H}+\mathrm{Al}=28,5 \mathrm{mmol}_{\mathrm{c}} / \mathrm{dm}^{3}$; $\mathrm{SB}=153,6 \mathrm{mmol} / \mathrm{dm}^{3} ; \mathrm{CTC}=182,1$ $\mathrm{mmol}_{\mathrm{c}} / \mathrm{dm}^{3} ; \mathrm{V}=84,35 \% ; \mathrm{Ca} / \mathrm{Mg}=1,52$ e $\mathrm{Mg} / \mathrm{K}=8,13$.

$\mathrm{O}$ delineamento experimental foi em blocos casualizados com seis tratamentos (substratos) e quatro repetições. A unidade experimental no viveiro foi constituída por dez mudas e no campo foi de 24 plantas da cultivar Vera em parcelas medindo 1,8x1,2 m, plantadas em quatro linhas dispostas no espaçamento de $30 \times 30 \mathrm{~cm}$. A área útil da parcela foi formada por 6 plantas das duas linhas centrais.

Os tratamentos constaram de substratos orgânicos contendo os seguintes condicionadores: casca de arroz carbonizada (T1); fibra de casca de coco (T2); composto orgânico (T3); substrato comercial Golden $^{\circledR}$ (T4); fibra triturada do caule da palmeira ouricurí (Attalea phalerata) (T5) e caule decomposto de sumaúma (Ceiba pentandra) (T6). Os substratos T3 e T4 foram considerados tratamentos controles; T3 por ser constituído 100\% de composto orgânico e recomendado na agricultura orgânica (Souza \& Rezende, 2006) e T4 por ser comercial. Os demais substratos (T1, T2, T5 e T6) apresentaram a seguinte composição: terra $(30 \%)$, composto orgânico $(30 \%)$, condicionador de substrato (30\%), fino de carvão (10\%), $1,0 \mathrm{~kg} / \mathrm{m}^{3}$ de calcário dolomítico, $1,5 \mathrm{~kg} /$ $\mathrm{m}^{3}$ de termofosfato natural e $1,0 \mathrm{~kg} / \mathrm{m}^{3}$ de sulfato de potássio.

A terra utilizada na confecção dos substratos foi retirada da camada superficial do solo onde foi instalado o experimento de campo.

A casca de arroz foi carbonizada em chapa de ferro aquecida com lenha. A fibra de casca de coco, fibra de palmeira e sumaúma foram triturados e 
posteriormente peneirados para melhor homogeneização.

As análises químico-físicas dos substratos foram feitas no Instituto Campineiro de Análise de Solo e Água (Tabelas 1 e 2).

A formação das mudas foi realizada em bandejas de poliestireno, sendo utilizada a cultivar Vera. Foram utilizadas três sementes por célula e oito dias após a semeadura, realizado desbaste, deixando uma planta por célula.

O transplante das mudas para o campo foi realizado 24 dias após a semeadura, em ambiente protegido com as laterais abertas, coberta com polietileno transparente de $100 \mu \mathrm{m}$, medindo $30 \times 4,6 \mathrm{~m}$, com 2,0 $\mathrm{m}$ de pé direito e 3,5 $\mathrm{m}$ de altura central. O preparo do solo constou de aração com arado de aiveca e gradagem com grade cultivadora de cinco facas e seis discos, ambos de tração animal. A adubação constou de 20 t/ha de composto orgânico (base seca) incorporado no momento de construção dos canteiros com enxada manual a 20 cm de altura.

A irrigação foi por microaspersão, sendo aplicado uma lâmina média de 6 $\mathrm{mm} /$ dia, elevando-se o teor de água no solo próximo à capacidade de campo, durante todo o ciclo da cultura. O controle de pragas e de doenças foi realizado com duas aplicações alternadas de calda sulfocálcica a $4 \%$ e óleo de nim a $1 \%$. Foram realizadas três capinas para o controle de plantas espontâneas, aos 10,20 e 30 dias após o transplantio. A colheita foi realizada aos 45 dias após o transplantio.

Foram avaliadas aos 24 dias após a semeadura, na fase de muda, as características: massa seca da parte aérea (MSPA), massa seca de raiz (MSR) e índice de qualidade do desenvolvimento da muda (IQD). No plantio a campo foram avaliados massa fresca comercial (MFC), massa seca da parte aérea comercial (MSPAC), produtividade comercial (PRODC) e classe comercial (5 a 100).

Para obtenção da altura de plantas foi utilizada régua graduada em centímetros, e com o auxílio do paquímetro mediu-se o diâmetro do colo da planta em mm. Para a determinação do IQD foi aplicada a metodologia de Dickson et al. (1960) determinado através das seguintes variáveis: massa seca da parte aérea, das raízes, massa seca total, altura e diâmetro do colo das mudas, conforme a equação:

$$
\begin{aligned}
& \mathrm{IQD}=\mathrm{MST} /[(\mathrm{H} / \mathrm{DC})+(\mathrm{MSPA} / \\
& \mathrm{MSRA})]
\end{aligned}
$$

Onde IQD = índice de qualidade de Dickson; MST= massa seca total $(\mathrm{g})$ $\mathrm{H}=$ altura $(\mathrm{cm}) ; \mathrm{DC}=$ diâmetro do colo $(\mathrm{mm}) ; \mathrm{MSPA}=$ massa seca da parte aérea (g); MSRA= massa seca da raiz (g).

Para a avaliação das características na fase de muda, as raízes foram lavadas em água corrente para retirada do substrato aderido e separado o sistema radicular da parte aérea. Para obtenção da massa seca da parte aérea e das raízes, as plantas foram acondicionadas em sacos de papel abertos e identificados e encaminhadas para estufas com circulação forçada de ar a $65^{\circ} \mathrm{C}$, até apresentarem massa constante aferindo-se depois a massa em uma balança analítica de precisão.

A massa fresca comercial foi obtida considerando a massa das plantas obtida após a retirada de folhas sujas, senescentes e doentes.

Para estimativa da produtividade comercial multiplicou-se a massa fresca comercial das plantas para cada metro quadrado de canteiro $\left(\mathrm{kg} / \mathrm{m}^{2}\right)$.

Para obter a massa da matéria seca da parte aérea, as plantas foram secas em estufa a $65^{\circ} \mathrm{C}$ até apresentarem massa constante.

Para obtenção da classe comercial, as plantas foram agrupadas de acordo com as normas do programa brasileiro para padronização da horticultura (Hortibrasil, 2007), de acordo com o limite inferior e superior de massa em gramas por planta (classes $5 \geq 100 \mathrm{~g} ; 10=100$ $\mathrm{a}<150 \mathrm{~g} ; 15=150 \mathrm{a}<200 \mathrm{~g} ; 20=200$ $\mathrm{a}<250 \mathrm{~g} ; 25=250 \mathrm{a}<300 \mathrm{~g} ; 30=300$ a $<350 \mathrm{~g}$; e assim sucessivamente até classe $100 \geq 1000 \mathrm{~g}$ ).

A análise estatística iniciou-se com a verificação de dados discrepantes (outliers) pelo teste de Grubbs, de normalidade dos erros pelo teste de Shapiro-Wilk e de homogeneidade das variâncias pelo teste de Cochran. Posteriormente efetuou-se análise de variância pelo teste $\mathrm{F}$ e comparação das médias dos tratamentos pelo teste de Scott-Knott. Para a variável massa seca

Tabela 1. Composição química dos substratos com diferentes condicionadores (chemical composition of substrates with different conditioners).

\begin{tabular}{|c|c|c|c|c|c|c|c|c|c|c|c|}
\hline \multirow{2}{*}{ Substratos } & \multirow{2}{*}{ pH } & $\mathbf{P}$ & $\mathbf{K}$ & $\mathrm{Ca}$ & Mg & $\mathbf{S}$ & B & $\mathbf{C u}$ & $\mathrm{Fe}$ & Mn & $\mathrm{Na}$ \\
\hline & & \multicolumn{10}{|c|}{$(\mathrm{mg} / \mathrm{L})$} \\
\hline Arroz & 7,5 & 5,9 & 184,0 & 108,0 & 408,0 & 36,3 & 0,21 & 0,02 & 3,76 & 0,12 & 10,0 \\
\hline Coco & 7,4 & 5,0 & 166,0 & 59,1 & 22,5 & 27,4 & 0,17 & 0,02 & 4,76 & 0,18 & 14,0 \\
\hline Composto & 6,2 & 30,2 & 69,0 & 221,0 & 80,2 & 46,3 & 0,18 & 0,10 & 4,82 & 5,47 & 8,4 \\
\hline Golden $^{\circledR}$ & 5,3 & 0,4 & 84,0 & 128,0 & 70,1 & 183,0 & 0,87 & 0,01 & 0,36 & 0,11 & 14,4 \\
\hline Palmeira & 6,5 & 20,2 & 348,0 & 153,0 & 88,0 & 87,1 & 0,28 & 0,03 & 1,99 & 0,82 & 12,0 \\
\hline Sumaúma & 8,1 & 2,3 & 140,0 & 130,0 & 410,0 & 35,2 & 0,10 & 0,03 & 3,61 & 0,15 & 9,4 \\
\hline
\end{tabular}
Rio Branco, UFAC, 2013. 
Tabela 2. Características físicas dos substratos com diferentes condicionadores \{physical characteristics of substrates with different conditioners \}. Rio Branco, UFAC, 2013.

\begin{tabular}{|c|c|c|c|c|c|c|c|c|}
\hline \multirow{2}{*}{ Substratos } & Da & Dp & EP & PS & CRA & \multirow{2}{*}{$\begin{array}{c}\mathrm{CTC} \\
(\mathrm{mmol} / \mathrm{kg})\end{array}$} & \multirow{2}{*}{$\frac{\mathrm{CE}}{(\mathrm{mS} / \mathrm{cm})}$} & \multirow{2}{*}{$\begin{array}{c}\text { M.O. } \\
(\mathrm{g} / \mathbf{1 0 0 g})\end{array}$} \\
\hline & \multicolumn{2}{|c|}{$\left(\mathrm{kg} / \mathrm{m}^{3}\right)$} & \multicolumn{3}{|c|}{$(\%)$} & & & \\
\hline Arroz & 720,6 & 2423,1 & 75,6 & 24,4 & 90,70 & 102,5 & 0,430 & 13,19 \\
\hline Coco & 589,9 & 2298,6 & 78,9 & 21,1 & 91,72 & 95,0 & 0,359 & 21,54 \\
\hline Composto & 649,5 & 2314,8 & 83,9 & 16,1 & 151,42 & 135,0 & 0,494 & 20,41 \\
\hline Golden $^{\circledR}$ & 454,0 & 1989,1 & 88,2 & 11,8 & 219,34 & 347,5 & 0,410 & 46,82 \\
\hline Palmeira & 779,3 & 2373,7 & 75,9 & 24,1 & 102,30 & 107,5 & 0,854 & 16,40 \\
\hline Sumaúma & 742,0 & 2380,3 & 76,9 & 23,1 & 106,60 & 160,0 & 0,489 & 15,90 \\
\hline
\end{tabular}

$\mathrm{Da}=$ densidade aparente (density); $\mathrm{Dp}=$ densidade das partículas (particle density); $\mathrm{EP}=$ espaço poroso (pore space); $\mathrm{PS}=$ partículas sólidas (solid particles); $\mathrm{CRA}=$ capacidade de retenção de água (water retention capacity); $\mathrm{CTC}=$ capacidade de troca de cátions (cation exchange capacity); $\mathrm{CE}=$ condutividade elétrica (electrical conductivity); M.O.= matéria orgânica (organic matter).

Tabela 3. $\mathrm{MSPA}=$ massa seca da parte aérea (shoot aboveground part dry matter); MSR= massa seca de raiz (root dry mass); IDQ= índice de qualidade de mudas (index of seedling quality) de alface cv. Vera, 24 dias após a semeadura, em função da utilização de diferentes substratos (of lettuce cv. Vera, 24 days after sowing, depending on the use of different substrates). Rio Branco, UFAC, 2013.

\begin{tabular}{|c|c|c|c|}
\hline \multirow{2}{*}{ Substratos } & MSPA & MSR & \multirow{2}{*}{ IQD $^{1}$} \\
\hline & \multicolumn{2}{|c|}{ (g/planta) } & \\
\hline Arroz & $0,037 \mathrm{a}$ & $0,011 \mathrm{a}$ & $0,0013 \mathrm{~b}$ \\
\hline Coco & $0,028 \mathrm{~b}$ & $0,009 \mathrm{~b}$ & $0,0012 b$ \\
\hline Composto & $0,038 \mathrm{a}$ & $0,008 \mathrm{~b}$ & $0,0011 \mathrm{~b}$ \\
\hline Golden $^{\circledR}$ & $0,008 \mathrm{c}$ & $0,005 \mathrm{c}$ & $0,0005 \mathrm{c}$ \\
\hline Palmeira & $0,038 \mathrm{a}$ & $0,013 \mathrm{a}$ & $0,0015 \mathrm{a}$ \\
\hline Sumaúma & $0,033 \mathrm{~b}$ & $0,009 \mathrm{~b}$ & $0,0011 \mathrm{~b}$ \\
\hline $\mathrm{CV}(\%)$ & 10,17 & 10,40 & 0,01 \\
\hline
\end{tabular}

Médias seguidas de mesma letra não diferem $(p>0,05)$ entre si pelo teste de Scott-Knott \{means followed by the same letter are not different $(\mathrm{p}>0.05)$ from each other by the ScottKnott test $\}$; ${ }^{1}$ Para a determinação do IQD foi aplicada a metodologia de Dickson et al. (1960) $\{$ IQD is determined by the methodology of Dickson et al. (1960) $\}$; IQD $=\{\mathrm{MST} /$ $[(\mathrm{H} / \mathrm{DC})+(\mathrm{MSPA} / \mathrm{MSRA})]\}$.

de raiz que não atendeu ao pressuposto de homogeneidade das variâncias efetuou-se a transformação dos dados para $\sqrt{\mathrm{x}}$. Para variável classe comercial, em que a mesma é determinada por notas pré-determinadas foi aplicado o teste não-paramétrico de Friedman.

\section{RESULTADOS E DISCUSSÃO}

Houve diferença significativa entre os substratos para as características massa seca da parte aérea, massa seca de raiz e índice de qualidade das mudas (Tabela 3). A massa seca da parte aérea de mudas produzidas com substratos contendo como condicionador: casca de arroz, composto orgânico e fibra de palmeira, não diferiu estatisticamente para estes condicionadores, porém, atingiram $470,8 \%$ mais massa seca da parte aérea que o substrato comercial Golden ${ }^{\circledR}$ utilizado como testemunha (Tabela 3). Os substratos contendo estes condicionadores apresentavam teores de $\mathrm{K}, \mathrm{Ca}$ e $\mathrm{Mg}$ adequados para substrato (Tabela 1), que segundo Plank (1989) é de 110 a $179 \mathrm{mg} / \mathrm{L}$ de K, 140 a $219 \mathrm{mg} / \mathrm{L}$ de Ca e 60 a $99 \mathrm{mg} / \mathrm{L}$ de $\mathrm{Mg}$.

$\mathrm{O}$ efeito benéfico da casca de arroz carbonizada quando adicionada ao substrato vem de suas características físicas que proporcionam boa drenagem, baixa densidade e água facilmente disponível, desde que sua concentração no substrato não ultrapasse $50 \% \mathrm{v} / \mathrm{v}$ (Rota \& Pauletti, 2008; Freitas et al., 2013; Castoldi et al., 2014).

O efeito benéfico do composto orgânico na produção da muda foi observado por Leal et al. (2011) em beterraba e alface e por Pereira et al. (2012) em almeirão. Segundo Cardoso et al. (2011), as características benéficas como condicionador são as concentrações elevadas de $\mathrm{Ca}, \mathrm{Mg}$, M.O., soma de base, capacidade de troca de cátions (CTC) e capacidade de retenção de água (CRA).

Apesar de não encontrar na literatura uso de caule de palmeira ouricurí (Attalea phalerata) como condicionador de substrato, Macedo et al. (2011) revelaram que outra palmeira muito semelhante, o babaçu (Attalea speciosa) em proporções de 20 a $60 \%$ de caule compondo o substrato proporcionaram mudas de alface de alta qualidade.

Nesta pesquisa, o substrato contendo caule de palmeira possui alta CRA, condutividade elétrica (CE), CTC, K, M.O., Ca, $\mathrm{S}$ e $\mathrm{Fe}$, características que contribuíram para o bom desempenho e qualidade das mudas (Tabelas $1 \mathrm{e} 2$ ).

O maior acúmulo de massa seca nas mudas desenvolvidas no composto orgânico ocorre pelo maior teor e equilíbrio dos nutrientes deste material. Cardoso et al. (2011), avaliando o efeito de doses de composto orgânico nas propriedades químicas do solo e teores de nutrientes para a produção de sementes de alface, utilizando as doses de: 30; 60; 90 e $120 \mathrm{t} /$ ha de composto orgânico e controle sem composto, observaram que a adição de composto orgânico no solo elevou os 
teores de M.O., Ca, Mg, SB, CTC e V\% do solo ao final do ciclo da cultura. O uso de composto orgânico como substrato propicia o desenvolvimento de mudas mais vigorosas (Pereira et al., 2012).

A massa seca de raiz (Tabela 3 ), segue a mesma tendência da massa seca da parte aérea (Tabela 3), exceto para o tratamento formado por composto orgânico que apresentou menor produção de massa seca de raiz quando comparado aos substratos casca de arroz e palmeira.

Este fato possivelmente é devido ao composto orgânico apresentar maior CRA (Tabela 2), e características químicas, suficiente para o desenvolvimento da planta com baixo desenvolvimento de raiz (Tabela 1). Apesar da composição química do substrato proporcionar maior acúmulo de massa seca da parte aérea, inibe o crescimento de raiz, reduzindo sua massa seca. Segundo Santos \& Carlesso (1998), o déficit hídrico estimula a expansão do sistema radicular para zonas mais profundas e úmidas do solo.

O substrato contendo estipe de palmeira picada como condicionador proporcionou maior IQD das mudas (Tabela 3).

O diâmetro do colo, associado à altura da planta são duas variáveis utilizadas no cálculo do IQD e revelam se houve estiolamento ou não. Segundo Cruz et al. (2006), a relação altura/diâmetro (RAD) imprime um equilíbrio no crescimento da muda, relacionando duas importantes características morfológicas em um único índice. Esta observação parte do princípio que plantas altas com diâmetro do colo pequeno podem ocorrer pela falta de luminosidade ou outro fator que estimule o crescimento vegetativo levando a planta a um possível estiolamento. Segundo Costa et al. (2011), a fórmula que determina o IQD é balanceada e inclui além da relação altura e diâmetro (RAD), as biomassas secas de raiz, parte aérea e total (IQD= MST/(RAD + RMS). Assim, quanto maior for o valor do índice, maior é o padrão de qualidade das mudas.

Provavelmente as proporções dos materiais que constituíram o substrato palmeira, em comparação com os demais, apresentaram superioridade por proporcionarem equilíbrio entre as características biométricas como diâmetro do colo, altura de planta e biomassa de raiz e parte aérea e por apresentar teores elevados de P, K e Ca (Tabela 1) e também características física adequadas para substratos como a disponibilidade de umidade, densidade, partículas sólidas e aeração (Tabela 2).

Apesar do substrato com palmeira apresentar o maior IQD (Tabela 3), os substratos contendo os condicionadores casca de arroz, fibra de casca de coco, palmeira e sumaúma não diferiram estatisticamente quanto à massa fresca comercial, massa seca da parte aérea comercial, produtividade e classe comercial e foram superiores ao substrato comercial (Tabela 4).

Segundo Oliveira et al. (2010), as hortaliças folhosas respondem muito bem à adubação orgânica. Considerando que a área onde se realizou o experimento é mantida com sistema orgânico há cinco anos, houve uma compensação fisiológica das plantas devido à qualidade química, física e biológica do solo. Souza (2005), avaliando as condições do solo de um sistema orgânico de produção por um período de cinco anos sob cultivo intercalado de varias hortaliças, verificou um aumento de 52\% de M.O., $326 \%$ em P (de 43 para $183 \mathrm{mg} / \mathrm{dm}^{3}$ ), $87 \%$ em K (de 3,55 para 6,64 $\mathrm{mmol}_{\mathrm{c}} /$ $\mathrm{dm}^{3}$ ), $71 \%$ em Ca e $88 \%$ em $\mathrm{Mg}$.

O substrato comercial Golden ${ }^{\circledR}$ promoveu a produção de mudas de qualidade inferior e menor produção comercial quando comparado aos demais tratamentos. Este substrato possui características físicas e físico-hídricas (Tabela 2) dentro dos padrões para substrato, porém, apresentou baixa concentração de $\mathrm{P}$, com apenas $0,4 \mathrm{mg} / \mathrm{dm}^{3}$ (Tabela1) provavelmente pela não adição de fósforo durante a linha de produção, do lote utilizado. Este teor está abaixo do ideal para substratos que variam de 8 a 13 mg/dm (Plank, 1989). Nessas concentrações o $\mathrm{P}$ favorece o desenvolvimento do sistema radicular, o vigor das plantas, a produção de matéria seca, aumenta a precocidade da colheita e as características pós-colheita de hortaliças (Filgueira, 2008).

Apesar da qualidade das mudas do substrato composto orgânico não diferir dos substratos casca de arroz, fibra de casca de coco e sumaúma (Tabela 3), proporcionou menor massa fresca comercial das plantas em campo (Tabela 4).

As mudas produzidas com composto orgânico tiveram maior desenvolvimento da parte aérea em detrimento do sistema radicular, com a maior relação MSPA/MSR, 4,8 (Tabela 3), valor bem acima daquele encontrado por Castoldi et al. (2014) que variou de 0,3 a 3,4 para mudas de alface que não diferiram no final do ciclo de campo. Segundo Mar-

Tabela 4. Massa fresca comercial, massa seca da parte aérea, produtividade e classe comercial de alface cv. Vera, aos 45 dias após o transplantio, em função da utilização de diferentes substratos (marketable fresh mass, aboveground part dry mass, yield and marketable class of lettuce cv. Vera, 45 days after transplanting, depending on the use of different substrates). Rio Branco, UFAC, 2013.

\begin{tabular}{lccccc}
\hline \multirow{2}{*}{ Substratos } & $\begin{array}{c}\text { Massa fresca } \\
\text { comercial }\end{array}$ & $\begin{array}{c}\text { Massa seca da } \\
\text { parte aérea }\end{array}$ & $\begin{array}{c}\text { Produtividade } \\
\left(\mathbf{k g} / \mathbf{m}^{2}\right)\end{array}$ & $\begin{array}{c}\text { Classe comercial } \\
\mathbf{( 5} \mathbf{~ a ~ 1 0 0 )}\end{array}$ \\
\cline { 2 - 3 } Arroz & $219,99 \mathrm{a}^{1}$ & $8,43 \mathrm{a}^{1}$ & & $2,44 \mathrm{a}^{1}$ & $18,8 \mathrm{a}^{2}$ \\
Coco & $230,28 \mathrm{a}$ & $8,79 \mathrm{a}$ & & $2,56 \mathrm{a}$ & $20,0 \mathrm{a}$ \\
Composto & $178,61 \mathrm{~b}$ & $6,82 \mathrm{~b}$ & & $1,98 \mathrm{~b}$ & $15,0 \mathrm{~b}$ \\
Golden ${ }^{\circledR}$ & $143,33 \mathrm{c}$ & $5,48 \mathrm{c}$ & & $1,59 \mathrm{c}$ & $12,5 \mathrm{~b}$ \\
Palmeira & $207,50 \mathrm{a}$ & $7,93 \mathrm{a}$ & & $2,31 \mathrm{a}$ & $20,0 \mathrm{a}$ \\
Sumaúma & $206,94 \mathrm{a}$ & $7,92 \mathrm{a}$ & & $2,30 \mathrm{a}$ & $18,8 \mathrm{a}$ \\
\hline CV (\%) & 11,20 & 11,16 & 11,20 & 15,06 \\
\hline
\end{tabular}

Médias seguidas de mesma letra não diferem ( $\mathrm{p}>0,05)$ entre si pelo teste de Scott-Knott; ${ }^{2}$ Médias seguidas de mesma letra não diferem $(p>0,05)$ entre si pelo teste de Friedman $\left\{{ }^{1}\right.$ average values followed by the same letter are not different $(p>0.05)$ by the Scott-Knott test; ${ }^{2}$ average values followed by the same letter are not different $(\mathrm{p}>0.05)$ by the Friedman test $\}$. 
ques et al. (2003), avaliando mudas de alface em bandejas de poliestireno com diferente número de células, verificaram que mudas com maior relação entre MFPA e MFR são indesejáveis para o transplante, em virtude da maior área foliar exposta à radiação solar, vento, e a pequena quantidade de raiz pode causar deficiência hídrica e de nutrientes, fazendo com que ocorra menor taxa de pegamento, desenvolvimento inicial lento, maior necessidade de replantio e maiores custos de produção.

Os substratos contento casca de arroz, fibra de casca de coco, sumaúma e palmeira proporcionaram as maiores produtividades variando de $2,30 \mathrm{a} 2,56 \mathrm{~kg} /$ $\mathrm{m}^{2}$ e classe comercial (Tabela 4). Neste caso, o menor IQD da muda dos substratos com os condicionadores casca de arroz, fibra de casca de coco, sumaúma não afetou a produtividade em campo em comparação com mudas de maior IQD produzidas com palmeira. Este comportamento também foi observado por Castoldi et al. (2014), avaliando substratos alternativos contendo vermiculita, basalto, casca de arroz e areia na produção de mudas de alface.

O substrato contendo palmeira como condicionador produz mudas orgânicas com maior IQD. No entanto, a qualidade inferior das mudas dos substratos contendo fibra de casca de coco, casca de arroz, composto orgânico e caule decomposto de sumaúma não reduz a produtividade da alface em cultivo orgânico e, portanto, também constituem alternativas viáveis para produção de muda orgânica de alface cv. Vera, podendo ser substituídos entre si.

\section{AGRADECIMENTOS}

À Coordenação de Aperfeiçoamento de Pessoal de Nível Superior (CAPES) e ao Conselho Nacional de Desenvolvimento Científico e Tecnológico (CNPq) pela concessão de bolsa aos autores.

\section{REFERÊNCIAS}

BARBOSA SC; MATTEUCCI MBA; LEANDRO WM; LEITE AF; CAVALCANTE ELS;
ALMEIDA GQE. 2011. Perfil do consumidor e oscilações de preços de produtos agroecológicos. Pesquisa Agropecuária Tropical 41: 602-609.

BARRETO CVG; TESTEZLAF R; SALVADOR CA. 2011. Ascensão capilar de água em substratos de coco e de pinus. Bragantia 71: 385-393.

CARDOSO AII; FERREIRA KP; VIEIRA JÚNIOR RM; ALCARDE C. 2011. Alterações em propriedades do solo adubado com composto orgânico e efeito na qualidade das sementes de alface. Horticultura Brasileira 29: 594-599.

CASTOLDI G; FREIBERGER MB; PIVETTA LA; PIVETTA LG; ECHER MM. 2014. Alternative substrates in the production of lettuce seedlings and their productivity in the field. Revista Ciência Agronômica 45: 299-304.

COSTA E; DURANTE LGY; NAGEL PL; FERREIRACR; SANTOS A. 2011. Qualidade de mudas de berinjela submetida a diferentes métodos de produção. Revista Ciência Agronômica 42: 1017-1025.

COSTA CA; RAMOS SJ; SAMPAIO RA; GUILHERME DO; FERNANDES LA. 2007. Fibra de coco e resíduo de algodão para substrato de mudas de tomateiro. Horticultura Brasileira 25: 387-391.

CRUZ CAF; PAIVA HN; GUERRERO CRA. 2006. Efeito da adubação nitrogenada na produção de mudas de sete-cascas (Samanea inopinata). Revista Árvore 30: 537-546.

DICKSON A; LEAF AL; HOSNER JF. 1960. Quality appraisal of white spruce and white pine seedling stock in nurseries. Forestry Chronicle 36: 10-13.

EMBRAPA. Centro Nacional de Pesquisa do Solo. 2013. Sistema brasileiro de classificação de solos. (2. ed.) Brasília: Embrapa. 353p.

FARIAS WC; OLIVEIRA LLP; OLIVEIRA TA; DANTAS LLGR; SILVA TAG. 2012. Caracterização física de substratos alternativos para produção de mudas. Revista ACSA 8: 1-6.

FERRAZ MV; CANTURION JF. BEUTLER AN. 2005. Caracterização física e química de alguns substratos comerciais. Acta Scientiarum. Agronomy 27: 209-214.

FILGUEIRA FAR. 2008. Novo manual de olericultura: agrotecnologia moderna na produção e comercialização de hortaliças. Viçosa: UFV.

FREITAS GA; SILVA RR; BARROS HB; VAZ-DE-MELO A; ABRAHÃO WAP. 2013. Produção de mudas de alface em função de diferentes combinações de substratos. Revista Ciência Agronômica 44: 159-166.

HORTIBRASIL. Instituto Brasileiro de Qualidade em Horticultura. 2007. Programa Brasileiro para a Modernização da Horticultura. Disponível em $<$ http://www.hortibrasil.org. $\mathrm{br} /$ classificacao/alface/alface.html $>$. Acessado em 02 agosto de 2007.

LEAL PAM; COSTA E; SCHIAVO JA;
PEGORARE AB. 2011. Seedling formation and field production of beetroot and lettuce in Aquidauana, Mato Grosso do Sul, Brazil. Horticultura brasileira, 29: 465-471.

LOPES JC; MAURI J; FERREIRA A; ALEXANDRE RS; FREITAS AR. 2012. Broccoli production depending on the seed production system and organic and mineral fertilizer. Horticultura Brasileira 30: 143-150.

MACEDO VRA; GUISCEM JM; CHAVES AMS; MONTEIRO ALR; BITU PIM; PINHEIRO GV. 2011. Avaliação do húmus do caule de palmeira do babaçu como substrato: característica química e sua viabilidade na produção de mudas de alface. In: Congresso Brasileiro de Agroecologia. 7. Fortaleza. Anais... Fortaleza: ASSOCIAÇ̃̃O BRASILEIRA DE AGROECOLOGIA. p. 1-5.

MARQUES PAA; BALDOTTO PV; SANTOS ACP; OLIVEIRA L. 2003. Qualidade de mudas de alface formadas em bandejas de isopor com diferentes números de células. Horticultura Brasileira 21: 649-651.

OLIVEIRA EQ; SOUZA RJ; CRUZ MCM; MARQUES VB; FRANÇA AC. 2010. Produtividade de alface e rúcula, em sistema consorciado, sob adubação orgânica e mineral. Horticultura Brasileira 28: 36-40.

PEREIRADC; GRUTZMACHER P; BERNARDI FH; MALLMANN LS; COSTA LAM; COSTA MSSM. 2012. Produção de mudas de almeirão e cultivo no campo, em sistema agroecológico. Revista Brasileira de Engenharia Agrícola e Ambiental 16: 1100-1106.

PLANK CO. 1989. Soil test handbook for Georgia. Athens: University of Georgia. 316p.

RODRIGUES ET; LEAL PAM; COSTA E; PAULA TS; GOMES VA. 2010. Produção de mudas de tomateiro em diferentes substratos e recipientes em ambiente protegido. Horticultura Brasileira, 28: 483-488.

ROTA LD; PAULETTI GF. 2008. Efeito da adição de casca de arroz em substrato comercial a base de turfa na produção de mudas de Viola tricolor L. Revista Brasileira de Agrociência, 14: 45-48.

SANTOS RF; CARLESSO R. 1998. Déficit hídrico e os processos morfológico e fisiológico das plantas. Revista Brasileira de Engenharia Agrícola e Ambiental 2: 287-294.

SILVA EMNCP; FERREIRA RLF; ARAÚJO NETO SE; TAVELLA LB; SOLINO AJS. 2011. Qualidade de alface crespa cultivada em sistema orgânico, convencional e hidropônico. Horticultura Brasileira 29: 242-245.

SOUZA JL. 2005. Agricultura orgânica: tecnologia para produção de alimentos saudáveis. Vitória: INCAPER. 257p.

SOUZA JL; RESENDE P. 2006. Manual de horticultura orgânica. Viçosa: UFV. 673p.

TRANI PE; FELTRIN DM; POTT CA; SCHWINGEL M. 2007. Avaliação de substratos para produção de mudas de alface. Horticultura Brasileira 25: 256-260. 